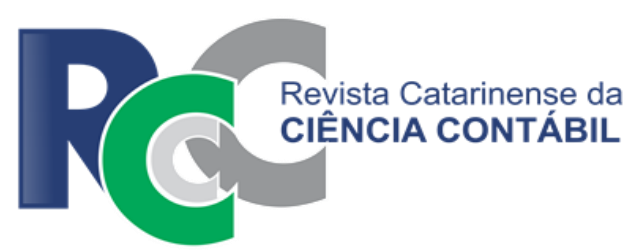
maio/ago. 2018

\title{
SUBVENÇÃO E ASSISTÊNCIA GOVERNAMENTAL EM EMPRESAS BRASILEIRAS COM FOMENTO À INOVAÇÃO DA FINEP
}

\section{GOVERNMENTAL GRANTS AND ASSISTANCE IN THE BRAZILIAN COMPANIES WITH INNOVATION FOSTERED BY FINEP}

\section{JACKELINE LUCAS SOUZA}

Doutora em Engenharia Civil pela Universidade Federal do Ceará (UFC). Professora adjunta da UFC. Endereço: Rua Torres Câmara, 891, Ap. 702 | Aldeota | 60150-060 | Fortaleza/CE / Brasil.

E-mail: jackeline.souza@hotmail.com

\section{PAULO HENRIQUE NOBRE PARENTE}

Doutorando em Ciências Contábeis pelo Programa de Pós-Graduação em Ciências Contábeis da Universidade Federal da Paraíba (PPGCCUFPB). Professor Efetivo do Ensino Básico, Técnico e Tecnológico do Instituto Federal de Educação, Ciência e Tecnologia do Ceará (IFCE). Endereço: Rua Valdemar Paes, 925 / Bom Jardim | 60545-055 / Fortaleza/CE / Brasil.

E-mail: paulonobreparente@gmail.com

\section{IVANEIDE FERREIRA FARIAS}

Mestranda no Programa de Pós- Graduação em Administração e Controladoria pela Universidade Federal do Ceará (UFC). Endereço: Rua Dona Mendinha, 1120 / Álvaro Weyne / 60336-035 / Fortaleza/CE | Brasil.

E-mail: ivaneideffarias@yahoo.com.br

\section{HYANE CORREIA FORTE}

Graduanda em Ciências Contábeis pela Universidade Federal do Ceará (UFC). Endereço: Rua Pedro Melo, 136 / Antônio Bezerra | 60360-220 / Fortaleza/CE / Brasil.

E-mail: hyane 0104@hotmail.com

\section{RESUMO}

Este estudo verifica o teor e o nível de evidenciação das Subvenções e Assistências Governamentais (SAG) nas demonstrações contábeis de empresas brasileiras beneficiadas pela Financiadora de Estudos e Projetos [FINEP], entre 2008 e 2015. O CPC 07 exige que as empresas divulguem a política contábil, a natureza e os montantes das subvenções governamentais, bem como as exigências que devem ser satisfeitas pelas empresas. Das 1.992 empresas beneficiadas no período, apenas 48 são de capital aberto e, consequentemente, publicam demonstrações contábeis no site da Bolsa, Brasil e Balcão [B3]. Utilizou-se análise de conteúdo, em que foram coletados dados cadastrais, setoriais, financeiros e contábeis das empresas, inclusive informações gerais das SAG. As informações relativas aos projetos financiados e/ou subsidiados foram obtidas no site da FINEP. A verificação do recebimento da SAG considerou as orientações do CPC 07 (2008) e de sua posterior revisão, CPC 07 - R1 (2010), que apresenta os oito itens sujeitos à divulgação. Observou-se que $71,2 \%$ das empresas da amostra evidenciaram o recebimento de SAG. 0 ano de 2009 foi o mais representativo, os outros $28,8 \%$ da amostra não demonstraram o 
recebimento de SAG, mas realizaram menção explícita quanto ao CPC 07. Conclui-se que, apesar da menção do CPC 07, parte representativa das empresas da amostra não divulgou as informações referentes às SAG, no período de 2010 a 2015, identificando maior evidência, somente, no ano de 2009.

Palavras-chave: Incentivos fiscais. Disclosure. Pronunciamentos contábeis. CPC 07.

\section{ABSTRACT}

This study verifies the content and level of disclosure of Government Grants and Assistance (GGA) in the financial statements of Brazilian companies fostered by the Studies and Projects Funding Entity [FINEP] between 2008 and 2015. CPC 07 requires companies to disclose their accounting policy, the nature and amounts of government grants, and the requirements that must be met by the companies. Of the 1,992 companies fostered during this period, only 48 are publicly-held and, consequently, publish financial statements on the Stock Exchange, Brazil, and over-the-counter [B3] website. We used the content analysis, in which we collected the companies' registration, sectorial, financial and accounting data, including general GGA information. We obtained information on the financed and subsidized projects from the FINEP website. The verification of receiving the GGA considered the guidelines of the CPC 07 (2008) and its subsequent review, CPC 07 - R1 (2010), which presents the eight items subject to disclosure. We verified that $71.2 \%$ of the sampled companies disclosed receiving the GGA. The year 2009 was the most representative. The other $28.8 \%$ of the sampled companies did not demonstrate receiving the GGA but explicitly mentioned the CPC 07. In conclusion, despite mentioning the CPC 07, a significant part of the sampled companies did not disclose the information regarding the GGA for the period between 2010 and 2015, showing greater disclosure only in 2009.

Keywords: Tax incentives. Disclosure. Accounting Pronouncements. CPC 07.

\section{INTRODUÇÃO}

A aprovação das Leis no 11.638, de 28 de dezembro de 2007, e n 11.941, de 27 de maio de 2009, e a publicação dos pronunciamentos técnicos pelo Comitê de Pronunciamentos Contábeis $[\mathrm{CPC}]$ representaram avanço da regulamentação societária brasileira, contribuindo para o processo de convergência contábil às normas internacionais. Como resultado, verificaram-se mudanças na estrutura das demonstrações contábeis, no aumento da qualidade da informação contábil, nos novos critérios de contabilização e na divulgação dos elementos patrimoniais e de resultado das empresas (Andrade \& Martins, 2009).

Dentre as modificações proporcionadas pelos normativos, a revogação da reserva de capital 'Doações e Subvenções para Investimento', conta que afeta o registro contábil da Subvenção e Assistência Governamental (SAG), deixou de ser reconhecida como reserva no patrimônio líquido das empresas e passou a ser registrada em conta de resultado do exercício. O reconhecimento no resultado somente ocorre quando atendidas as condições de reconhecimento de receita (Martins, Gelbcke, Santos, \& ludícibus, 2013) e faz com que essa constatação produza aproximação da relação lucro-caixa (Nogueira, Jucá \& Macedo, 2010).

Essa alteração é proposta no Pronunciamento Técnico do CPC 07 - Subvenção e Assistência Governamental - promulgado em 2008, modificado pelo CPC 07 - R1, aprovado pela Deliberação CVM n 646, de 2 de dezembro de 2010 (Comissão de Valores Mobiliários [CVM], 2010) - e a visa alinhar os padrões contábeis à norma internacional IAS 20, emitida pelo International Accounting Standards, que disciplina as transações desenvolvidas entre o setor público e o privado.

As SAG configuram-se como programas administrados e viabilizados pelos governos da União, Estados e Distrito Federal e Municípios, que objetivam o incremento de operações, a atração de investimentos regionais com necessidade de desenvolvimento, bem como o fomento às atividades diversas de interesse público (Taveira, 2009). Destaque-se que as concessões de subvenções configuram-se como potencial e necessário campo de pesquisa 
nas áreas de administração e contabilidade, pois os tributos impactam diretamente no resultado contábil e patrimônio das empresas (Formigoni, 2008).

Nesse contexto, destaca-se o apoio da Financiadora de Estudos e Projetos [FINEP] na promoção do desenvolvimento tecnológico no Brasil, por meio de programas de incentivo à inovação (Inovar, Juro Zero, Subvenção Econômica e Subvenção Pesquisador/Empresa). Tais programas desenvolvem-se por meio de financiamentos subsidiados, subvenção econômica e escoamento de capital (Macaneiro \& Cherobim, 2009). Destaca-se a dimensão dos recursos envolvidos. A FINEP, entre 2008 e 2016, liberou cerca de $R \$ 16,2$ bilhões para projetos com características inovadoras, conforme dados apresentados ao final deste estudo.

Ao considerar a representatividade dos valores envolvidos pelas SAG, concedidas pelo governo às empresas brasileiras, questiona-se: de que forma é realizada a evidenciação de SAG pelas empresas brasileiras beneficiadas pela FINEP, conforme requerem os CPC 07 (2008) e CPC 07 - R1 (2010)? O estudo teve o objetivo geral de verificar o teor e o nível de evidenciação das SAG nas demonstrações contábeis de empresas brasileiras beneficiadas pela FINEP. Adicionalmente, estudo analisa também a relação entre o nível de evidenciação e a representatividade das SAG recebidas.

A amostra da pesquisa está composta por 48 empresas brasileiras de capital aberto, distribuídas entre 2008 e 2015, identificadas pela coleta de informações disponibilizadas nas demonstrações contábeis e publicadas na Brasil, Bolsa, Balcão [B3] e no site da FINEP.

Em termos contábeis, após o processo de convergência, bem como após a aprovação do Pronunciamento Contábil CPC 07 - R1 (2010), o tratamento contábil dado às SAG passou por modificações significativas. Os aspectos contábeis da SAG e os respectivos efeitos na empresa foram estudados por Taveira (2009), Chagas, Araújo e Damascena (2011), Loureiro, Gallon e De Luca (2011), Rodrigues, Silva e Faustino (2011), Benetti, Benetti, Utzig, Braun e Oro (2014) e Barros, Souza e Dalfior (2015).

Os resultados do estudo mostram que $71,2 \%$ das empresas evidenciaram subvenções e assistências governamentais, demonstradas por meio do recebimento de incentivos fiscais. As empresas receberam $6,11 \%$ e $17,70 \%$ de SAG e de projetos das FINEP em relação ao ativo total. Ademais, observou-se que as empresas receberam até $69,7 \%$ e 532,0\% de SAG e de projetos da FINEP em relação aos ativos totais e patrimônio líquido, respectivamente.

É relevante considerar que as empresas brasileiras têm encontrado dificuldades na obtenção de financiamentos externos para inovação (Crisóstomo, 2009), o que motiva o Governo a promover o desenvolvimento da inovação no país (Hamburg, 2010), por meio das subvenções governamentais, dentre essas as fornecidas pela FINEP. Busca, com isso, justificar o contexto de análise da pesquisa, limitando-se à perspectiva de a empresa retornar à sociedade o recurso recebido, realizar a devida prestação de contas e o atendimento às normas de contabilidade, como determinam o CPC 07 (2008) e CPC 07 - R1 (2010).

Este artigo está dividido em seis seções. Essa primeira, a introdução da pesquisa, seguida da fundamentação teórica, na qual estão abordadas as subvenções e assistências governamentais no contexto da convergência contábil e as pesquisas realizadas sobre o tema. Na sequência, a seção dos procedimentos metodológicos apresenta as técnicas e os métodos utilizados na execução da investigação. A seção seguinte reúne os resultados e a discussão. Finalmente, as considerações finais apontam os resultados, as limitações e sugestões para futuras pesquisas.

\section{FUNDAMENTAÇÃO TEÓRICA}

\subsection{Convergência contábil e subvenções e assistências governamentais}

O processo de convergência das normas contábeis brasileiras às normas internacionais iniciou a partir da promulgação da Lei no 11.638 (2007), alterando e revogando os dispositivos da Lei no 6.404 (1976) e da Lei no 6.385 (1976) (Crispim, 2011). Nesse contexto, foi instituído o Comitê de Pronunciamentos Contábeis [CPC], com o propósito de estudar, analisar, elaborar e emitir pronunciamentos técnicos sobre os procedimentos contábeis a serem adotados pelas instituições (Barros et al., 2015). 
Essas modificações impactaram a contabilidade das empresas, resultando em uma nova estrutura para as demonstrações contábeis, cujo foco passou a ser a prevalência da essência econômica sobre a forma do evento, com novos critérios de contabilização e divulgação dos elementos patrimoniais e de resultados, afetando a qualidade da informação contábil (Andrade \& Martins, 2009).

Dentre as modificações inseridas na legislação societária, cita-se a segregação da contabilidade voltada para as demonstrações contábeis, direcionada a fins fiscais (ludícibus, Martins, Gelbcke, \& Santos, 2010) e às inovações nos registros contábeis. Tais inovações impactaram o lucro, as reservas e os dividendos das entidades, como no caso do registro das subvenções e assistências governamentais [SAG], que passaram a ser contabilizadas em conta de resultado ao invés de reserva no patrimônio líquido. Dessa forma, o registro da SAG como receita passou a ocorrer no momento de seu recebimento, desde que tenham sido cumpridas as condições necessárias à sua efetivação (ludícibus et al., 2010; Loureiro et al., 2011).

No contexto contábil internacional, o assunto sobre doações e subvenções tem sido tratado na International Accounting Standards - IAS 20, emitida em 1983 e revisada em 1994 pelo International Accouting Standards Board [IASB] (Barros et al., 2015). No Brasil, no intuito de regulamentar essa atividade em consonância com a IAS 20, foi criado o Pronunciamento Técnico CPC 07, aprovado pela Norma Brasileira de Contabilidade Técnica [NBCT] 19.4 Subvenção e Assistência Governamentais, por meio da Resolução no 1.143 (2008), do Conselho Federal de Contabilidade [CFC] e pela Deliberação CVM no 555 (2008) (CPC, 2010).

No CPC 07 são apresentados os procedimentos aplicáveis na contabilização e na divulgação de subvenção governamental, bem como as modalidades de transações realizadas entre o setor público (governo) e o privado (empresas) (CPC, 2010). Destaca-se que a Deliberação CVM no 646 (2010) regulamentou a alteração do CPC 07 para CPC 07 (R1). Trouxe modificações, principalmente, quanto aos critérios de divulgação das SAG.

Em conformidade com as alterações proporcionadas pela Lei $n=6.404$ (1976), o CPC 07 - R1 (2010) apresenta argumentos para justificar o reconhecimento da SAG como receita na demonstração do resultado do exercício (DRE), entre os quais: (a) a subvenção não deve ser creditada diretamente no patrimônio líquido, e sim reconhecida como receita nos períodos apropriados, pois é recebida de fontes não acionistas e deriva de ato de gestão em benefício da entidade; (b) raramente é gratuita e a entidade ganha efetivamente essa receita quando cumpre as regras das SAG e determinadas obrigações e (c) assim como os tributos são despesas reconhecidas na DRE, a SAG é uma extensão da política fiscal. Deve, também, ser reconhecida e registrada no resultado.

A SAG poderá ser reconhecida quando existir segurança razoável de que a empresa cumprirá todas as condições estabelecidas. Da subvenção, após transitar pelo resultado do exercício, poderá, a partir da conta de lucros ou prejuízos acumulados, ocorrer o crédito em reserva própria, como acúmulo de incentivos fiscais (CPC, 2010).

No que diz respeito aos itens que devem ser divulgados nas demonstrações contábeis, o CPC 07 (2008) orientava que as empresas com SAG deveriam divulgar, no mínimo, as seguintes informações: (a) a política contábil e os métodos de apresentação adotados para as SAG; (b) a natureza e a extensão reconhecidas das SAG, bem como a indicação de outras formas de assistência governamental de que a entidade tenha diretamente se beneficiado; (c) condições a serem regularmente satisfeitas ligadas à SAG que tenha sido reconhecida; (d) descumprimento de condições relativas à SAG ou existência de outras contingências; (e) o prazo em que a SAG permanecerá na entidade; (f) eventuais SAG a reconhecer contabilmente, após cumpridas as condições contratuais; (g) premissas utilizadas para o cálculo do valor justo e (h) informações relativas às parcelas aplicadas em fundos de investimentos regionais e às reduções ou isenções de tributos em áreas incentivadas. Com as alterações inseridas pelo CPC 07 - R1 (2010), o quantitativo de itens que devem ser divulgados pelas empresas foi reduzido, disciplinando que apenas as informações apontadas nos itens (a), (b) e (c) devem ser divulgadas.

O CPC 07 - R1 (2010) define assistência governamental como uma "ação de um governo destinada a fornecer benefício econômico específico a uma entidade ou a um grupo de entidades que atendam a critérios estabelecidos", enquanto que a subvenção 
governamental é definida como "assistência governamental geralmente na forma de contribuição pecuniária, mas não só restrita a ela, concedida a uma entidade normalmente em troca do cumprimento passado ou futuro de condições relacionadas às atividades operacionais da entidade" (CPC 07 - R1, 2010, p.2).

Loureiro et al. (2011) e Chagas et al. (2011, p. 9) detalham a diferença entre subvenção e assistência. A primeira tem natureza pecuniária, enquanto a segunda "pode ser realizada através de outras ações de natureza não pecuniária". Fonteneles, Ponte, Oliveira e Ribeiro (2014) acrescentam que SAG são os subsídios oferecidos às empresas pelo governo, com o intuito de estimular o desenvolvimento socioeconômico de um determinado local.

Crispim (2011) aponta que as subvenções variam de acordo com a natureza e as condições em que ocorrem. Podem ser incentivos fiscais, empréstimos subsidiados, subsídios em empréstimos, contribuições, entre outros. As subvenções objetivam atrair investimentos e estimular determinado setor econômico ou região, incrementando operações e financiando a promoção de atividades de interesse público. Podem ser concedidas por governos das esferas municipais, estaduais e federais (Taveira, 2009; Barros et al., 2015).

Nesse contexto, as subvenções podem auxiliar a implementação de diversos projetos, como aqueles operacionalizados por órgãos como a FINEP, que atua diretamente na promoção do desenvolvimento da inovação do país. Nesse sentido, a subvenção governamental atuaria como fator propulsionador do desenvolvimento da inovação (Hamburg, 2010). A participação do governo deve ser considerada, visto que o processo de inovação deve ser encarado como uma questão político-institucional (Silva \& Costa, 2012).

A FINEP tem fomentado a inovação no Brasil por meio de alguns programas, como o projeto Inovar, Juro Zero, Subvenção Econômica e Subvenção Pesquisador/Empresa. A FINEP, em conjunto com o Banco Nacional de Desenvolvimento Econômico e Social [BNDES] e o Conselho Nacional de Desenvolvimento Científico [CNPq], tem contribuído para inovação no Brasil (Macaneiro \& Cherobim, 2009). Os programas governamentais desenvolvidos pela FINEP têm sido realizados por meio da concessão de bolsas de pesquisa, financiamentos subsidiados (reembolsável), subvenção econômica (não reembolsável) e escoamento de capital (Macaneiro \& Cherobim, 2009).

As empresas brasileiras têm optado por buscar, entre as entidades governamentais, recursos oriundos de subvenção, como uma forma de auxílio à inovação (Corder \& Sales-Filho, 2006). O provimento de recursos destinados aos investimentos iniciais às empresas inovadoras deve decorrer do setor público, uma vez que os investidores de maior porte preferem investir apenas nas fases futuras (Corder \& Sales-Filho, 2006). Desse modo, as subvenções teriam papel fundamental na implementação e alavancagem dos projetos de inovação.

\subsection{Estudos anteriores}

As mudanças inseridas pelo CPC 07 - R1 (2010) suscitaram o desenvolvimento de pesquisas a respeito de como as empresas têm reconhecido e divulgado as SAG. No entanto, ainda são escassos os estudos a respeito desse assunto. Dentre os estudos realizados, destacam-se: Taveira (2009), Chagas et al. (2010), Loureiro et al. (2011), Rodrigues et al. (2011), Benetti et al. (2014) e Barros et al. (2015).

Taveira (2009) avaliou como as empresas de capital aberto, classificadas nos segmentos diferenciados de governança corporativa da BM\&FBovespa, observaram as orientações do CPC 07 (2008) divulgadas nas demonstrações contábeis de 2008. Os resultados do estudo evidenciaram informações contábeis com nenhum ou pouco detalhamento em itens que exigem maiores níveis de explicações, ou seja, não satisfazendo aos critérios definidos pelo CPC 07 (2008).

Chagas et al. (2010) verificaram as subvenções e assistências governamentais obtidas pelas Organizações da Sociedade Civil de Interesse Público [OSCIPs], da Paraíba e do Rio Grande do Norte, evidenciadas conforme o CPC 07 (R1) (2010) e a NBCT 19.14 - Resolução CFC no 1.143 (2008). Os resultados apontaram que grande parte das OSCIPs evidenciou as subvenções e assistências governamentais em obediência ao Pronunciamento Técnico do CPC 07 - R1 (2010) e da NBCT 19.14. 
Loureiro et al. (2011) investigaram a divulgação das informações e os efeitos econômicos decorrentes do reconhecimento das SAG nas demonstrações contábeis das 100 maiores companhias abertas do Brasil, listadas na revista Exame, entre 2008 e 2009, conforme o CPC 07 - R1 (2010). As autoras observaram que as empresas apresentaram baixos níveis de evidenciação, maior evidenciação do item política contábil adotada para as SAGs, incluindo os métodos de apresentação adotados nas demonstrações contábeis, além de considerável participação das SAG no capital próprio das empresas dos setores têxtil e papel e celulose.

Rodrigues et al. (2011) pesquisaram as empresas sediadas no Estado de Pernambuco, que receberam subvenções oriundas de incentivos fiscais do IR e do ICMS, durante o período de 2007 a 2009. Objetivou-se identificar como foram evidenciados os registros contábeis das subvenções governamentais e se estavam em conformidade com as orientações do CPC 07 R1 (2010). Dentre os resultados apontados, apenas $31 \%$ das demonstrações contábeis analisadas cumpriram as orientações do CPC.

Benetti et al. (2014) verificaram se o nível de evidenciação das SAG das empresas listadas na BM\&FBovespa, no período de 2010, estava em conformidade com o Pronunciamento Técnico do CPC 07 - R1 (2010). Constatou-se que o item política contábil adotada pela entidade para subvenções governamentais foi o mais evidenciado, seguido do item referente aos métodos de apresentação e evidenciação da natureza e dos montantes de SAG.

Barros et al. (2015) investigaram o grau de aplicação do CPC 07 - R1 (2010) em empresas da administração pública indireta do Estado de Minas Gerais, no exercício de 2013. Os resultados apontam que das 15 empresas analisadas, sete não receberam subvenções e assistências governamentais, três receberam e não aplicaram o que determina o CPC e três aplicaram parcialmente. Apenas duas empresas apresentaram conformidade total, nas demonstrações contábeis, com o CPC 07 - R1 (2010).

Gonçalves, Nascimento e Wilbert (2016) analisaram se as empresas brasileiras que receberam subvenções governamentais apresentaram maior nível de elisão fiscal e se geraram mais riqueza para a sociedade. Os resultados mostram que as empresas beneficiadas com as SAG apresentaram maior nível de elisão fiscal em relação aos tributos sobre o lucro e agregaram menor valor aos bens e serviços gerados.

O presente estudo se distingue dos demais ao analisar a aderência de empresas de capital aberto do Brasil, beneficiadas pelos programas da FINEP entre 2008 e 2015, em relação à evidenciação de SAG, exigida pelo CPC 07 - R1 (2010). Convém destacar a relevância da análise do perfil de todas as entidades beneficiadas pela FINEP e a análise da representatividade das empresas de capital aberto listadas na $\mathrm{B} 3$, em relação a todas as empresas beneficiadas pela FINEP, bem como sua associação com o nível de evidenciação.

\section{PROCEDIMENTOS METODOLÓGICOS}

A metodologia do estudo classifica-se como descritiva, uma vez que busca identificar o teor e o nível de divulgação de subvenções e assistências governamentais. A coleta de dados secundários, caracterizada como documental, foi realizada no site da B3 e da Finep. A análise de dados caracteriza-se como quali-quantitativa.

O universo da pesquisa compreende todas as empresas que foram beneficiadas pela FINEP, totalizando 1.992 entidades. Dessas, 48 são empresas de capital aberto que, consequentemente, publicam demonstrações contábeis no site da B3. Assim, a amostra é representada apenas por 48 empresas e 66 projetos submetidos e aprovados - 2,4\% da população do estudo.

A não aleatoriedade na definição das empresas de capital aberto deu-se em determinação ao objetivo do estudo. A aprovação da Resolução $n^{\circ} 1.143 / 08$, do Conselho Federal de Contabilidade [CFC], determina que a norma deve ser aplicada na contabilização e divulgação da subvenção governamental, bem como em outras formas de assistência governamental.

Partiu-se para análise de conteúdo das demonstrações contábeis - Balanço Patrimonial, Demonstração do Resultado do Exercício e Notas Explicativas - das empresas 
entre 2008 e 2015, divulgadas no portal da CVM, de onde foram coletados dados cadastrais, setoriais, financeiros e contábeis, inclusive informações gerais das SAG. As informações relativas aos projetos financiados e/ou subsidiados foram obtidas no site da FINEP.

Inicialmente, verificou-se se as empresas evidenciaram em notas explicativas o recebimento da SAG em cada um dos períodos em análise. Caso a empresa não possuísse SAG, atribuiu-se valor zero (0); do contrário, valor um (1). Classificou-s tal benefícios como Federal (F), Estadual (E) e/ou Municipal (M), dependendo da origem do recurso público. Para as empresas que evidenciaram o recebimento de SAG, foi realizada análise do nível e do teor das informações contidas nas notas explicativas e os itens requeridos pelo CPC 07 (2008) e CPC 07 - R1 (2010), de acordo com a Figura 1.

As informações analisadas nas notas explicativas foram confrontadas com as informações presentes na base de dados da FINEP, a fim de identificar se e como as empresas classificam os projetos de SAG recebidos pela FINEP, bem como sua representatividade em relação ao total de SAG das empresas.

Tabela 1

Itens de evidenciação das SAG de verificação nas Notas Explicativas

\begin{tabular}{c|l}
\hline Item & \multicolumn{1}{c}{ Informação a ser divulgada pelas empresas (CPC 07, 2008) } \\
\hline 1 & $\begin{array}{l}\text { A política contábil adotada para as subvenções governamentais, incluindo os métodos de apresentação } \\
\text { adotados nas demonstrações contábeis. }\end{array}$ \\
\hline 2 & $\begin{array}{l}\text { A natureza e os montantes reconhecidos das subvenções governamentais ou das assistências } \\
\text { governamentais, bem como a indicação de outras formas de assistência governamental de que a entidade } \\
\text { se tenha diretamente beneficiado. }\end{array}$ \\
\hline 3 & $\begin{array}{l}\text { As condições a serem regularmente satisfeitas ligadas à assistência governamental que tenha sido } \\
\text { reconhecida. }\end{array}$ \\
\hline 4 & O descumprimento de condições relativas às subvenções ou à existência de outras contingências. \\
\hline 5 & O prazo em que a subvenção permanecerá na entidade. \\
\hline 6 & Eventuais subvenções a reconhecer contabilmente, após cumpridas as condições contratuais. \\
\hline 7 & As premissas utilizadas para o cálculo do valor justo exigido pela regulamentação contábil. \\
\hline 8 & $\begin{array}{l}\text { As informações relativas às parcelas aplicadas em fundos de investimentos regionais e às reduções ou } \\
\text { isenções de tributos em áreas incentivadas. }\end{array}$ \\
\hline Fonte: Adaptado do Pronunciamento Técnico do CPC 07 (2008).
\end{tabular}

Para identificar o nível de disclosure, optou-se pela evidenciação relacionada a cada item de divulgação prescrito no Pronunciamento Técnico do CPC 07 (2008). Seguindo esse critério, quando a informação foi evidenciada nas notas explicativas no período de estudo, aplicou-se (1) e (0). Caso contrário, no total e no máximo, aplicou-se oito pontos. Acrescentase que o CPC 07 - R1 (2010) torna obrigatória somente a evidenciação dos itens 1, 2, e 3.

No site da FINEP, foram obtidas informações acerca dos projetos submetidos pelas empresas, bem como a modalidade, o valor do projeto e o liberado. Os projetos submetidos, quanto à modalidade, podem ser classificados em reembolsável e não reembolsável. O primeiro refere-se aos financiamentos subsidiados, enquanto que o segundo se remete à subvenção econômica. Ao submeterem os projetos na FINEP, as empresas apresentam valor proposto para sua realização. No entanto, cabe à FINEP a sua liberação, o que nem sempre representa o valor sugerido.

A análise dos dados, de caráter qualitativo, foi dividida em três etapas: (i) perfil das instituições e das SAG recebidas; (ii) nível e teor da evidenciação de informações requeridas pela norma da SAG; (iii) representatividade das SAG em contas da empresa e (iv) análise da representatividade dos valores recebidos pelas empresas de SAG e dos projetos da FINEP em relação ao ativo total e ao patrimônio líquido das empresas. A priori, expõe-se um panorama das instituições que foram beneficiadas pela FINEP, no período entre 2008 e 2015, para, então, mostrar a representatividade da SAG das empresas de capital aberto do Brasil em relação às demais. Posteriormente, apresenta-se o nível e o teor da evidenciação das informações exigidas pelo CPC 07 (2008) e CPC 07 - R1 (2010). Por fim, examina-se a representatividade das SAG em relação ao ativo total e ao patrimônio líquido da empresa. 


\section{ANÁLISE DE RESULTADOS}

\subsection{Análise dos resultados}

No período de 2008 a 2015, foram enviados ao FINEP 3.930 projetos, dos quais 3.577 receberam recursos. Pode-se verificar na Tabela 2 que 0 ano com mais projetos financiados pelo FINEP foi o de 2010, com total de 780 projetos. Em segundo lugar ficou o ano de 2008, com 638 projetos. Verifica-se também queda no número de projetos financiados nos três últimos anos. Quanto à modalidade, verificou-se que a maioria dos financiamentos é do tipo sem reembolso, com total de 2.920 projetos sem reembolso e 605 com reembolso.

Constatou-se, ainda, por meio da Tabela 2, que, dos 3.525 projetos que receberam financiamentos do FINEP, apenas 75 são de empresas listadas na B3 e a maioria das instituições não listadas são universidades, centros ou associações de pesquisa. Acrescentese que, ao longo dos oito anos, o número de projetos de empresas participantes da B3 decresceu.

Tabela 2

Análise dos projetos financiados pelo FINEP

\begin{tabular}{|c|c|c|c|c|c|c|c|c|c|c|c|}
\hline & Atributos & 2008 & 2009 & 2010 & 2011 & 2012 & 2013 & 2014 & 2015 & Total & $\%$ \\
\hline Projetos FINEP & $\mathrm{N}$ & 638 & 617 & 780 & 390 & 375 & 453 & 229 & 43 & 3.525 & 100,0 \\
\hline \multirow{2}{*}{ Modalidade } & Reembolsável & 62 & 71 & 86 & 144 & 94 & 124 & 24 & 0 & 605 & 17,2 \\
\hline & Não reembolsável & 576 & 546 & 694 & 246 & 281 & 329 & 205 & 43 & 2.920 & 82,8 \\
\hline \multirow{3}{*}{$\begin{array}{l}\text { Empresas Listadas } \\
\text { na B3 }\end{array}$} & Sim & 5 & 18 & 14 & 9 & 9 & 13 & 6 & 1 & 75 & 2,1 \\
\hline & Não & 633 & 599 & 766 & 381 & 366 & 440 & 223 & 42 & 3.450 & 97,9 \\
\hline & Norte & 38 & 27 & 38 & 19 & 9 & 20 & 6 & 1 & 158 & 4,5 \\
\hline \multirow{4}{*}{$\begin{array}{l}\text { Projetos/Regiões } \\
\text { do Brasil }\end{array}$} & Nordeste & 133 & 79 & 126 & 42 & 52 & 73 & 33 & 1 & 539 & 15,3 \\
\hline & Centro-Oeste & 35 & 32 & 52 & 23 & 20 & 26 & 10 & 2 & 200 & 5,7 \\
\hline & Sudeste & 286 & 327 & 395 & 181 & 203 & 216 & 121 & 28 & 1.757 & 49,8 \\
\hline & Sul & 146 & 152 & 169 & 125 & 91 & 118 & 59 & 11 & 871 & 24,7 \\
\hline
\end{tabular}

Fonte: Dados da pesquisa.

Observa-se que a FINEP aprovou 3.525 projetos às entidades para o desenvolvimento de projetos de inovação. $82,8 \%$ dos projetos financiados caracterizam-se como não reembolsáveis, ou seja, não possuem caraterística de financiamento. Não é necessária a devolução do recurso recebido pela empresa. É perceptível que parte representativa das entidades (97,9\%), que foram beneficiadas pela FINEP, não estão listadas na bolsa de valores.

Os resultados mostram, também, que a região Sudeste teve 1.757 projetos financiados pela FINEP, no período de 2008 a 2015. Ficou em segundo lugar a região Sul, com total de 871 projetos financiados. O mesmo pôde ser observado quando na análise de cada ano, separadamente, ou seja, $74,5 \%$ das empresas beneficiadas estão nas regiões Sul e Sudeste.

Em continuidade à verificação dos projetos, procedeu-se à análise descritiva dos recursos liberados, no período de 2008 a 2015, observando o valor médio de $\mathrm{R} \$ 4.491 .345,80$ para financiamento, conforme apresentado na Tabela 3.

Tabela 3

Análise descritiva dos recursos liberados para os projetos pela FINEP

\begin{tabular}{|c|c|c|c|c|c|c|c|}
\hline Período & $\mathbf{N}$ & Mínimo & Máximo & Média & Cresc. (\%) & DP & CV \\
\hline 2008 & 638 & $16.913,30$ & $100.000 .000,00$ & $2.813 .203,20$ & - & $8.817 .623,30$ & 3,10 \\
\hline 2009 & 617 & $2.448,00$ & $100.000 .000,00$ & $4.194 .144,50$ & 0,49 & $11.577 .941,30$ & 2,80 \\
\hline 2010 & 780 & $41.595,00$ & $93.229 .363,00$ & $3.146 .147,70$ & $-0,25$ & $9.087 .378,80$ & 2,90 \\
\hline 2011 & 390 & $13.425,00$ & $93.840 .000,00$ & $4.011 .453,40$ & 0,28 & $9.882 .670,30$ & 2,50 \\
\hline 2012 & 375 & $1.912,00$ & $126.000 .000,00$ & $3.565 .683,00$ & $-0,11$ & $11.580 .265,80$ & 3,20 \\
\hline 2013 & 453 & $38.100,00$ & $321.804 .051,00$ & $10.914 .141,80$ & 2,06 & $32.790 .867,50$ & 3,00 \\
\hline 2014 & 229 & $58.500,00$ & $240.292 .166,00$ & $5.828 .529,50$ & $-0,47$ & $20.752 .198,10$ & 3,60 \\
\hline 2015 & 43 & $80.000,00$ & $7.000 .000,00$ & $1.457 .463,00$ & $-0,75$ & $1.485 .212,10$ & 1,00 \\
\hline Total & 3525 & $1.912,00$ & $321.804 .051,00$ & $4.491 .345,80$ & $-0,28$ & $9.490 .105,50$ & 2,10 \\
\hline
\end{tabular}

Fonte: Dados da pesquisa.

O período com maior amplitude em relação aos valores dos projetos de inovação foi entre 2013 e 2015. Apresenta diferença de $R \$ 9,5$ milhões. Os valores dos projetos sofreram 
quedas significativas, de $-87,0 \%$, entre 2013 e 2015, possivelmente em decorrência da crise financeira do Estado e da situação da crise econômica. Constatou-se, também, que os coeficientes de variação foram elevados, o que sugere alta variabilidade dos valores liberados, o que pode indicar diversidade de valores monetários investidos nos projetos.

Observou-se na Tabela 3 que a taxa de crescimento médio dos valores dos projetos apresenta conduta oscilatória entre os períodos, com aumentos e reduções intervalares. 0 período de 2015 é representado por uma queda brusca no número de projetos atendidos pela FINEP.

Para análise inicial, consideraram-se as empresas que efetivamente mencionaram incentivo nas demonstrações contábeis. A Figura 1 ilustra o quantitativo de projetos (não) aprovados pela FINEP às empresas durante o período de análise.

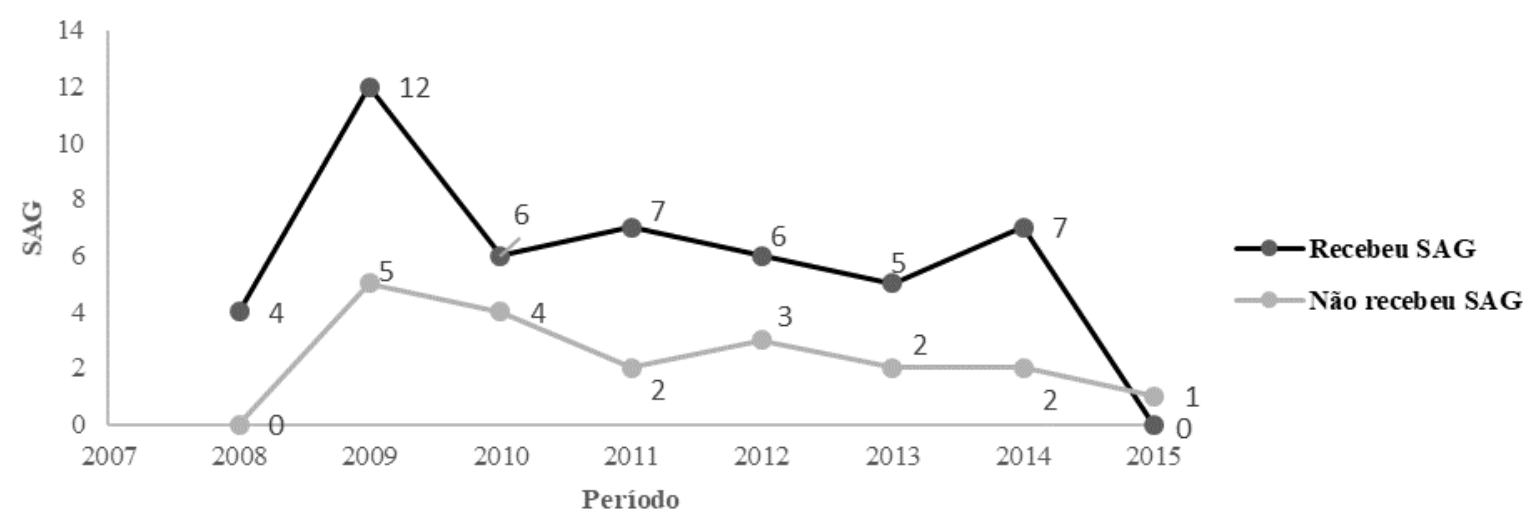

Figura 1. Evolução de projetos aprovados pela FINEP às empresas brasileiras de capital aberto do Brasil

Fonte: Dados da pesquisa.

De modo geral, $71,2 \%$ das empresas da amostra evidenciaram o recebimento de SAG. Observa-se na Figura 1 que o ápice de recebimento de SAG pelas empresas ocorreu em 2009, com total de 12 benefícios (29,3\%). Além disso, é possível observar, na Tabela 4, a partir da publicação do CPC 07 - R1 (2010), que as empresas evidenciaram níveis constantes de recebimento de SAG entre 2010 e 2015, de acordo com a origem dos recursos (federais, estaduais ou municipais).

A evidenciação de SAG nas empresas apresenta comportamento semelhante, quando comparado com o quantitativo de projetos aprovados pela FINEP. Indica que as subvenções e assistências proporcionadas ao Governo foram sendo reduzidas desde 2010.

Tabela 4

Evidenciação e menção ao CPC 07 - R1 pelas empresas beneficiadas pela FINEP

\begin{tabular}{lcccc}
\hline \multirow{2}{*}{ Evidenciação e Origem da SAG } & \multicolumn{2}{c}{ Recebimento SAG } & \multicolumn{2}{c}{ Menção ao CPC 07 } \\
Não evidenciou SAG & $\mathbf{N}$ & $(\%)$ & $\mathbf{N}$ & (\%) \\
\hline Evidenciou SAG & 19 & 28,8 & 13 & 86,7 \\
$\quad$ Federal & 47 & 71,2 & 8 & 53,3 \\
$\quad$ Estadual & 24 & 36,3 & 1 & 6,7 \\
Municipal & 12 & 18,2 & 0 & 0,0 \\
Federal e Estadual & 0 & 0,0 & 4 & 26,7 \\
$\quad$ Federal, Municipal e Estadual & 11 & 16,7 & 0 & 0,0 \\
\hline Total & 0 & 0,0 & $\mathbf{1 5}$ & $\mathbf{1 0 0 , 0}$ \\
\hline
\end{tabular}

Fonte: Dados da pesquisa.

Os resultados mostram que $28,8 \%$ das empresas não evidenciaram o recebimento de SAG. Todavia, realizaram menção explícita quanto ao CPC 07. Além disso, é possível observar que, das empresas que receberam SAG, 24 (36,3\%) têm origem federal, $12(18,2 \%)$ estadual e nenhuma empresa apresentou origem municipal. Parte representativa dessas subvenções 
recebidas estão sob a forma de incentivos fiscais. Foi apresentado nas notas explicativas, principalmente, a redução da parcela do Imposto de Renda Pessoa Jurídica [IRPJ], devido ou não.

Além disso, muito embora as empresas sejam beneficiadas pelo governo, não realizam menção ao CPC 07, mesmo que a amostra do estudo tenha acontecido entre a divulgação da primeira versão do CPC 07 (2008) e cinco anos após a versão do CPC 07 R1 (2010).

No que diz respeito às informações qualitativas evidenciadas, verifica-se, na Tabela 5 , que 33 empresas (50\%) utilizaram a terminologia Incentivo Fiscal para se referir à SAG e, em segundo lugar, seis empresas utilizaram a terminologia Subsídio ou outras para abordar o benefícios a SAG. Constatou-se, ainda, que 11 empresas (16,7\%) não informaram a SAG recebida.

Tabela 5

Informações qualitativas evidenciadas em notas explicativas

\begin{tabular}{|c|c|c|c|}
\hline Informações evidenciadas em & as explicativas & $\mathbf{N}$ & $\%$ \\
\hline \multirow{6}{*}{ Terminologia utilizada para informar a SAG recebida } & Subsídio & 6 & 9,1 \\
\hline & Incentivo fiscal & 33 & 50,0 \\
\hline & Doação & 2 & 3,0 \\
\hline & Prêmio & 4 & 6,1 \\
\hline & Outra & 6 & 9,1 \\
\hline & Não informou & 11 & 16,7 \\
\hline \multirow{4}{*}{ Característica da SAG recebida } & Ativo monetário & 32 & 48,5 \\
\hline & Ativo não monetário & 16 & 24,2 \\
\hline & Monetário e não monetário & 2 & 3,0 \\
\hline & Não informou & 12 & 18,2 \\
\hline \multirow{2}{*}{ Relação entre a SAG recebida e a FINEP } & Sim & 1 & 1,5 \\
\hline & Não & 65 & 98,5 \\
\hline Total & & 66 & 100,0 \\
\hline
\end{tabular}

Fonte: Dados da pesquisa.

A Tabela 5 evidencia que $48,5 \%$ das empresas da amostra têm caracterizado as SAG nas notas explicativas como ativo monetário. Ficou em segundo lugar a descrição como ativo não monetário $(24,2 \%)$. Constata-se também que $65(98,5 \%)$ das empresas da amostra não evidenciaram relação entre a SAG e a FINEP, ou seja, não informaram fonte dos recursos. Em complemento a essa análise, a Tabela 6 aponta empresas que divulgam os itens obrigatórios do CPC 07.

Tabela 6

Nível de atendimento aos itens do CPC 07 e CPC 07 - R1 Nível de Atendimento dos Itens nas Notas Explicativas - CPC 07 (2008)

\begin{tabular}{|c|c|c|c|c|c|c|c|c|c|c|c|c|}
\hline & \multicolumn{10}{|c|}{ Itens obrigatórios } & \multirow{2}{*}{\multicolumn{2}{|c|}{ Média Geral }} \\
\hline & 1 & \multicolumn{2}{|c|}{2} & 3 & \multicolumn{2}{|c|}{4} & 5 & 6 & 7 & 8 & & \\
\hline Divulgado & 33,3 & \multicolumn{2}{|c|}{19,0} & 14,3 & \multicolumn{2}{|c|}{4,8} & \multirow{2}{*}{$\frac{9,5}{90,5}$} & 0,0 & 4,8 & 4,8 & \\
\hline Não divulgado & 66,7 & \multicolumn{2}{|c|}{81,0} & 85,7 & \multicolumn{2}{|c|}{95,2} & & 100,0 & 95,2 & 95,2 & \multicolumn{2}{|c|}{8} \\
\hline \multicolumn{11}{|c|}{ Nível de Atendimento dos Itens nas Notas Explicativas - CPC 07 - R1 (2010) } & \multicolumn{2}{|c|}{88,7} \\
\hline & \multicolumn{3}{|c|}{ Itens obrigatórios } & \multirow{2}{*}{\multicolumn{2}{|c|}{$\begin{array}{c}\text { Média } \\
\text { Parcial }\end{array}$}} & \multicolumn{5}{|c|}{ Itens voluntários } & \multirow{2}{*}{$\begin{array}{l}\text { Média } \\
\text { Parcial }\end{array}$} & \multirow{2}{*}{$\begin{array}{l}\text { Média } \\
\text { Geral }\end{array}$} \\
\hline & 1 & 2 & 3 & & & 4 & 5 & 6 & \begin{tabular}{|l|}
7 \\
\end{tabular} & 8 & & \\
\hline Divulgado & 51,1 & 26,7 & 20,0 & 32 & & 4,4 & 8,9 & 2,2 & 4,4 & 2,2 & 4,4 & 15,0 \\
\hline Não divulgado & 48,9 & 73,3 & 80,0 & 67 & & 95,6 & 91,1 & 97,8 & 95,6 & 97,8 & 95,6 & 85,0 \\
\hline
\end{tabular}

Para o nível de atendimento dos itens evidenciados em Notas Explicativas, no período de 2008 a 2009, aplica-se o CPC 07 (2008), enquanto que no período de 2010 a 2015 aplicase o CPC 07 R1 (2010).

Dessa forma, a Tabela 6 evidencia que em média 11,3\% das empresas da amostra divulgaram os itens obrigatórios do CPC 07. Ao analisar cada item, pôde-se constatar que a maioria das empresas não divulgou os itens 1 (66,7\%), $2(81,0 \%), 3(85,7 \%), 4(95,2 \%), 5$ $(90,5 \%), 6(100,0 \%), 7$ (95,2) e 8 (95,2\%). Mesmo sendo a divulgação obrigatória, verifica-se, que no período de 2008 a 2009, a maioria das empresas que recebeu SAG não seguiu as recomendações do CPC 07. 
Quanto ao período de 2010 a 2015, a Tabela 7 apresenta que $32,6 \%$ das empresas divulgaram os itens obrigatórios e $4,4 \%$ expuseram os itens voluntários. No geral, apenas $15 \%$ das empresas da amostra apresentaram os itens obrigatórios e voluntários. Ao se analisar cada item, separadamente, verifica-se que dos três itens obrigatórios do CPC 07 - R1 (2010), somente o item 1 apresentou maior percentual de divulgação (51,1\%). Os itens 2 e 3 não foram divulgados pela maioria das empresas, num percentual de divulgação de $73,3 \%$ e $80,0 \%$, respectivamente. Quanto aos itens voluntários, a grande parte da amostra não evidenciou as informações referentes a esses itens.

Além disso, constata-se que nos dois períodos o item "política contábil adotada para as subvenções governamentais" foi o mais evidenciado. A Tabela 7 apresenta a representatividade da SAG e dos recursos da FINEP no ativo total e no patrimônio líquido. Assim, dentro de 66 projetos financiados, em um valor médio da FINEP de $R \$ 33.836 .514,75$, quarenta e um projetos, em um valor médio de $R \$ 614.175,00$, foram contemplados com SAG e 14 evidenciaram Reserva de Incentivos Fiscais (RIF), no valor médio de $R \$ 285.902,00$.

Tabela 7

Representatividade da SAG e da FINEP no ativo total e no patrimônio líquido

\begin{tabular}{|c|c|c|c|c|c|c|}
\hline \multicolumn{7}{|c|}{ PAINEL A - Valores (em R\$ mil) relativos à FINEP, SAG e RIF } \\
\hline Variáveis & $\mathrm{N}$ & Média (\%) & Mediana (\%) & Mínimo (\%) & Máximo (\%) & DP \\
\hline FINEP & 66 & 33.837 & 14.371 & 139 & 240.292 & 4,39 \\
\hline SAG & 41 & 614.175 & 15.622 & 60 & 4.569 .660 & $1.123,28$ \\
\hline RIF & 14 & 285.902 & 82.929 & 5.347 & 1.849 .893 & 509,78 \\
\hline \multicolumn{7}{|c|}{ PAINEL B - Representatividade das SAG e FINEP } \\
\hline Variáveis & $\mathrm{N}$ & Média (\%) & Mediana (\%) & Mínimo (\%) & Máximo (\%) & DP \\
\hline SAG/AT & 41 & 6,11 & 18,61 & 0,03 & 27,34 & 7,64 \\
\hline SAG/PL & 41 & 16,54 & 4,67 & 0,06 & 69,71 & 23,08 \\
\hline FINEP/AT & 66 & 17,70 & 3,85 & 0,00 & 352,00 & 47,93 \\
\hline FINEP/PL & 66 & 17,38 & 8,89 & 0,00 & 253,83 & 51,12 \\
\hline
\end{tabular}

Nota. FINEP: representa os valores recebidos pelas empresas da FINEP, independentemente da modalidade; SAG: denota a subvenção recebida pelo governo RIF: remete à reserva de incentivos fiscais; SAG/AT e SAG/PL: refere-se à razão entre a SAG recebida e o ativo total e patrimônio líquido, respectivamente; FINEP/AT e FINEP/PL: diz respeito ao valor liberado pela FINEP sobre o ativo total e o patrimônio líquido, respectivamente.

Fonte: Dados da pesquisa.

Os resultados mostram que as empresas apresentam valores superiores de SAG em relação aos recursos fornecidos pela FINEP, uma vez as empresas obtêm outras formas de captar incentivos em diferentes esferas governamentais, conforme apresentado na Tabela 5. Outro resultado evidencia que $46,5 \%$ dos recursos recebidos são destinados para a reserva de incentivos fiscais. Além disso, reforça-se que nem todas as empresas que receberam recursos da FINEP realizaram a devida evidenciação em Notas Explicativas, conforme determinam 0 CPC 07 (2008) e CPC 07 - R1 (2010).

Constata-se também que a razão entre os recursos SAG e o ativo é de 6,11 , ou seja, cada $R \$ 1,00$ do ativo equivale ao valor médio $S A G$ de $R \$ 6,11$ e cada $R \$ 1,00$ do patrimônio líquido equivale ao valor médio SAG de $R \$ 16,54$. No caso dos recursos advindos da FINEP, mesmo com participação de todas as empresas da amostra, verifica-se a representatividade em relação ao ativo e ao patrimônio líquido maior do que a da SAG, o que pode ser constatado tanto nos valores médios de $R \$ 17,70$ (em relação ao ativo) e de $R \$ 17,38$ (em relação ao patrimônio líquido), como nos valores máximos de $R$ \$ 352,00 (em relação ao ativo) e $R$ \$ 253,83 (em relação ao patrimônio líquido).

Esses resultados são, de fato, significativos, considerando que do total da composição de ativos e patrimônio líquido, 17\%, aproximadamente, são referentes aos recursos disponibilizados pela FINEP. Todavia, é interessante observar que as medidas de representatividade da FINEP apresentam elevada variabilidade, com índices de 47,9 (em relação ao ativo total) e 51,1 (em relação ao patrimônio líquido). 


\subsection{Discussão dos resultados}

As empresas beneficiadas pela FINEP apresentaram baixos níveis de evidenciação de informações sobre subvenções e assistências governamentais. Somente $22,7 \%$ fizeram menção ao CPC 07 e CPC 07 (R1) e dessas somente uma empresa relacionou a SAG recebida pela FINEP. Tais resultados evidenciam a significativa desconformidade às exigências das normas, considerando principalmente, a representatividade dos valores recebidos pelas empresas.

Os resultados mostram também o baixo nível de evidenciação das informações nas demonstrações contábeis, com médias de 11,3\% e 15,0\% em relação ao CPC 07 e CPC 07 (R1), respectivamente. Esses resultados corroboram os estudos de Taveira (2009), Loureiro et al. (2011), Rodrigues et al. (2011) e Barros et al. (2015), que observaram em pesquisas baixos níveis de evidenciação dos níveis de atendimento do CPC 07 (2008) ou CPC 07 (R1) (2010). Portanto, não confirmam os achados de Benetti et al. (2014) e Chagas et al. (2010), que apontaram que as empresas por eles analisadas têm divulgado as subvenções governamentais de acordo com o CPC 07 - R1 (2010).

Nesse sentido, é relevante que a empresa encare o cumprimento de informações obrigatórias e seus benefícios, como, por exemplo, a percepção, por parte dos investidores, de que a empresa está preocupada com os diversos stakeholders, principalmente quanto ao governo e aos investidores.

Mesmo após as alterações do CPC 07 (2008), o nível de evidenciação de informações mostrou-se significativamente baixo. Não atendem a qualquer nível de informação a ser divulgada, conforme classificam Hendriksen e Van Breda (1999). Nesse sentido, cabe questionar, se, de fato, o baixo nível de evidenciação de informações está atendendo aos objetivos da Contabilidade.

Quanto ao item mais evidenciado, assim como esta pesquisa, Loureiro et al. (2011) e Benetti et al. (2014) constataram que o item 'política contábil adotada para as subvenções governamentais' tem sido citado como mais frequência nas demonstrações contábeis.

Outros apontamentos referem-se à representatividade dos valores recebidos, pois quando verificada a representação das SAG e dos recursos da FINEP, recebidos com o ativo total e com o patrimônio líquido, a média é de 11,3\% e 17,5\%, respectivamente. Nessa direção, Loureiro et al. (2011) verificaram considerável participação das SAG no capital próprio das empresas dos setores têxtil e papel e celulose. Essas evidências mostram a relevância dos recursos públicos recebidos pelas empresas e fortalece a necessidade de maior cumprimento às normas contábeis e de fiscalização pelos organismos contábeis.

\section{CONCLUSÃO}

O presente estudo teve como objetivo geral verificar o teor e o nível de evidenciação das Subvenções e Assistências Governamentais [SAG] nas demonstrações contábeis das empresas brasileiras beneficiadas pela FINEP, considerados como objetivos específicos: (i) traçar o perfil das instituições favorecidas pelos financiamentos da FINEP; (ii) identificar se as empresas de capital aberto do Brasil evidenciaram o reconhecimento da SAG nas duas demonstrações contábeis, verificando o teor das informações evidenciadas em relação à origem das SAG; (iii) examinar o nível de atendimento dos requisitos de divulgação do CPC 07 (2008) e CPC 07 - R1 (2010) nas empresas de capital aberto e (iv) analisar a relação entre a evidenciação e a representatividade das SAG.

Para o primeiro objetivo específico, verificou-se que as organizações mais beneficiadas por esse financiamento são as universidades e centros de pesquisas, locais em que há incentivo à realização de projetos que visam ao desenvolvimento científico e tecnológico do país. Além disso, pôde-se constatar que as organizações mais beneficiadas pelo FINEP estão concentradas nas regiões Sul e Sudeste do país.

No que tange ao segundo objetivo específico, considerando as alterações ocorridas em 2007 e 2009 na legislação societária brasileira, as que provocaram mudanças no registro contábil da subvenção e assistência governamental [SAG], pôde-se perceber elevado percentual de empresas $(71,2 \%)$ que evidenciaram a SAG em seus demonstrativos financeiros. 
As maiores evidenciações de SAG foram de subvenções recebidas na forma de incentivos fiscais. Cita-se, principalmente, a redução na parcela do Imposto de Renda Pessoa Jurídica (IRPJ).

Para o terceiro objetivo específico proposto, dos oito itens de evidenciação obrigatórios, tratados no CPC 07 (2008), item 43 - revisado no CPC 07 - R1 (2010), sobre subvenção e assistência governamental [SAG], verificou-se baixa preocupação por parte das organizações em apresentar as informações relativas às SAG recebidas, tendo em vista o baixo percentual de empresas de capital aberto que demonstraram tais informações, principalmente, no CPC 07 - R1 (2010). Os itens obrigatórios são somente três, e não mais oito, como tratados no CPC 07 (2008) - antes da revisão de 2010.

Em relação ao último objetivo específico, observou-se, além dos valores relativos à FINEP e à SAG recebidos pelas empresas, a representatividade desses valores em relação ao ativo total e ao patrimônio líquido. Em média, as empresas receberam $6,11 \%$ e $17,70 \%$ de SAG e de projetos das FINEP em relação ao ativo total. Essa representatividade é relativamente superior quando comparada com o patrimônio líquido das empresas. Ademais, observou-se que as empresas receberam até $69,7 \%$ e $532,0 \%$ de SAG e de projetos da FINEP em relação aos ativos totais e patrimônio líquido. Esses indicadores mostram a representação e relevância dessas cifras na estrutura patrimonial das empresas.

Pesquisas futuras poderão analisar os financiamentos realizados pelo FINEP, acessando os dados de prestação de contas das empresas beneficiadas junto com a Financiadora de Estudos e Projetos [FINEP], para que, assim, seja possível verificar a realização dos projetos elaborados e em quais locais os recursos de SAG foram efetivamente alocados.

\section{REFERÊNCIAS}

Andrade, M. E. M. C. \& Martins, V. A. (2009). Análise dos normativos de contabilidade internacional sobre contabilização de contratos de parcerias público - privadas. Revista Contemporânea de Contabilidade, 1(11), 83-107.

Barros, E. L., Souza, C. A., \& Dalfior, V. A. O. (2015, outubro) Aplicação do CPC 07 (R1) Subvenção e Assistência Governamentais em empresas da administração pública indireta do Estado de Minas Gerais. Anais do Simpósio de Excelência em Gestão e Tecnologia, Rio de Janeiro, RJ, Brasil, 12.

Benetti, K., Benetti, K., Utzig, M. J. S., Braun, M., \& Oro, I. M. (2014). Evidenciação de subvenção e assistência governamentais das empresas na BM\&FBOVESPA. Revista Evidenciação Contábil \& Finanças, 2(1), 75-90.

Chagas, M. J. R., Araujo, A. O., \& Damascena, L. G. (2011). Evidenciação das subvenções e assistências governamentais recebidas pelas OSCIPs: Uma análise empírica nos estados da Paraíba e do Rio Grande do Norte. Revista Ambiente Contábil, 3(2), 100-115.

Comitê de Pronunciamentos Contábeis (CPC). Pronunciamento Técnico CPC 07 (R1), de 05 de novembro de 2010. (2010). Subvenção e assistência governamentais. 2010. Aplicado na contabilização e na divulgação de subvenção governamental e na divulgação de outras formas de assistência governamental. Recuperado em 15 dezembro, 2016, de http://www.cpc.org.br/pronunciamentosIndex.php

Comitê de Pronunciamentos Contábeis (CPC). Pronunciamento Técnico CPC 07, de 03 de outubro de 2008. (2008). Subvenção e assistência governamental. 2008. Aplicado na contabilização e na divulgação de subvenção governamental e na divulgação de outras formas de assistência governamental. Recuperado em 4 dezembro, 2016, de http://www.cpc.org.br/pdf/CPC_07.pdf 
Comissão de Valores Mobiliários (2010). Deliberação CVM no 646, de 02 de dezembro de 2010. (2010). Aprova o Pronunciamento Técnico CPC 07 (R1) do Comitê de Pronunciamentos Contábeis, que trata de subvenção e assistência governamentais. Recuperado em 15 fevereiro, 2017, de http://www.cvm.gov.br/export/sites/cvm/legislacao/deliberacoes/anexos/0600/deli646.pdf

Comissão de Valores Mobiliários (2010). Deliberação CVM no 555, de 12 de novembro de 2008. (2008). Aprova o Pronunciamento Técnico CPC 07 do Comitê de Pronunciamentos Contábeis, que trata de Subvenções e Assistências Governamentais. Recuperado em 10 fevereiro, 2017 , http://www.cvm.gov.br/export/sites/cvm/legislacao/deliberacoes/anexos/0500/deli555.pdf

Comissão de Valores Mobiliários (2010). Instrução CVM no 469, de 02 de maio de 2008. (2008). Dispõe sobre a aplicação da Lei no 11.638, de 28 de dezembro de 2007. Altera as Instruções CVM no 247, de 27 de março de 1996 e 331, de 4 de abril de 2000. Recuperado em $10 \quad$ fevereiro, $2017, \quad$ de http://www.normaslegais.com.br/legislacao/instrucaocvm469_2008.htm

Comissão de Valores Mobiliários (2010). Instrução CVM no 059, de 22 de dezembro de 1986. (1986). Dispõe sobre a obrigatoriedade de elaboração e publicação da demonstração das mutações do patrimônio líquido pelas companhias abertas. Recuperado em 11 fevereiro, 2017 , http://www.cvm.gov.br/export/sites/cvm/legislacao/instrucoes/anexos/001/inst059.pdf

Conselho Federal de Contabilidade (CFC). Resolução no 1.143, de 21 de novembro de 2008. (2008). Aprova a NBC T 19.4 - Subvenção e Assistência Governamentais. Recuperado em 28 dezembro, 2016, de http://www.normaslegais.com.br/legislacao/resolucaocfc1143_2008.htm

Corder, S. \& Salles-Filho, S. (2006). Aspectos conceituais do financiamento à inovação. Revista Brasileira de Inovação, 5(1), 33-76.

Crispim, G. (2011). Subvenção governamental sob a ótica do CPC 07: reconhecimento contábil após a Lei no 11.638/2007 nas entidades privadas no Estado de Pernambuco. Dissertação de mestrado, Universidade Federal de Pernambuco, Recife, PE, Brasil.

Crisóstomo, V. L. (2009). Dificuldades das empresas brasileiras para financiar seus investimentos em capital físico e em inovação. Revista de Economia Contemporânea, 13(2), 259-280.

Fonteneles, I. V., Ponte, V. M. R., Oliveira, M. C., \& Ribeiro, M. S. (2014, setembro). Assistências Governamentais e Disclosure Socioambiental. Anais do Encontro Nacional da Associação Nacional de Pós-Graduação e Pesquisa em Administração, Rio de Janeiro, RJ, Brasil, 38.

Formigoni, H. (2008). A influência dos incentivos fiscais sobre a estrutura de capital e a rentabilidade das companhias abertas brasileiras não financeiras. Tese de doutorado, Universidade de São Paulo, São Paulo, SP, Brasil.

Gonçalves, R. S., Nascimento, G. G. do, Wilbert, M. D. (2016). Os efeitos da subvenção governamental frente à elisão fiscal e a geração de riqueza. Revista Catarinense da Ciência Contábil, 15(45), 34-48.

Hamburg, M. A. (2010). Innovation, Regulation, and the FDA. New England Journal of Medicine, 363(23), 2228-2232. 
Hendriksen, E. S. \& Van Breda, M. F. (1999). Teoria da Contabilidade. São Paulo: Atlas.

ludícibus, S., Martins, E., Gelbcke, E. R., \& Santos, A. (2010). Manual de Contabilidade Societária: aplicável a todas as sociedades de acordo com as normas internacionais e do CPC. São Paulo: Atlas.

Lei $n^{0}$ 11.941, de 27 de maio de 2009. (2009). Altera a legislação tributária federal relativa ao parcelamento ordinário de débitos tributários; institui regime tributário de transição e dá outras providências. Recuperado em 20 janeiro, 2017, de http://www.planalto.gov.br/ccivil_03/_ato2007-2010/2009/lei/l11941.htm

Lei $n^{\circ}$ 11.638, de 28 de dezembro de 2007. (2007). Altera e revoga dispositivos da Lei $n^{\circ} 6.404$, de 15 de dezembro de 1976, e da Lei no 6.385, de 7 de dezembro de 1976, e estende às sociedades de grande porte disposições relativas à elaboração e divulgação de demonstrações financeiras. Recuperado em 19 janeiro, 2017, de http://www.planalto.gov.br/ccivil_03/_ato2007-2010/2007/lei/l11638.htm

Lei $n^{\circ}$ 6.404, de 15 de dezembro de 1976. (1976). Dispõe sobre as sociedades por ações. Recuperado em 15 janeiro, 2017, de http://www.planalto.gov.br/CCivil_03/Leis/L6404compilada.htm

Lei $n^{\circ}$ 6.385, de 7 de dezembro de 1976. (1976). Dispõe sobre o mercado de valores mobiliários e cria a Comissão de Valores Mobiliários. Recuperado em 11 outubro, 2017, de http://www.planalto.gov.br/ccivil_03/leis/L6385.htm

Loureiro, D. Q., Gallon, A. V., \& De Luca, M. M. M. (2011). Subvenções e Assistências Governamentais (SAG): Evidenciação e Rentabilidade das Maiores Empresas Brasileiras. Revista de Contabilidade e Organizações, 5(13), 34-54.

Macaneiro, M. B. \& Cherobim, A. P. M. (2009). O financiamento da inovação tecnológica por meio de programas governamentais de apoio às empresas brasileiras. Revista de Administração, Contabilidade e Economia, 8(2), 291-324.

Martins, E., Gelbcke, E. R., Santos, A., \& ludícibus, S. (2013). Manual de Contabilidade Societária: Aplicável a todas as sociedades (2a ed.). São Paulo: Atlas.

Nogueira, E., Júnior, Jucá, M. N., \& Macedo, M. A. S. (2010). O impacto da harmonização das práticas contábeis brasileiras às internacionais na relação entre o lucro líquido e o fluxo de caixa operacional. Revista Contabilidade Vista \& Revista. 23(1), 47-74.

Rodrigues, R., N., Silva, G. C., \& Faustino, O. W. C. (2011). Subvenção e assistência governamental sob a ótica do CPC 07: reconhecimento contábil após a lei 11.638/2007 nas entidades privadas no Estado de Pernambuco. Registro Contábil - RECONT, 2(3), $35-45$.

Silva, R. G. L. \& Costa, M. C. (2012). Tecnologia e política industrial na organização dos espaços de inovação. Revista Economia \& Tecnologia, 8(1), 111-128.

Taveira, J. H. P. S. (2009). Conformidade do disclosure das subvenções governamentais nas empresas de capital aberto. Dissertação de mestrado, Faculdade de Economia e Finanças IBMEC, Rio de Janeiro, Brasil. 